\title{
Slug inhibition increases radiosensitivity of nasopharyngeal carcinoma cell line C666-1
}

\author{
HONGXIA YANG $^{1 *}$, GANG ZHANG $^{2 *},{\text { XIAOLIN } \mathrm{CHE}^{3} \text { and SHUDONG YU }}^{4}$ \\ ${ }^{1}$ Department of Otorhinolaryngology, Maternal and Child Health Hospital of Tai'an; ${ }^{2}$ Department of Otolaryngology, \\ Affiliated Hospital of Taishan Medical University, Tai'an, Shandong 271000; ${ }^{3}$ Department of Otolaryngology, \\ Shandong University of Traditional Chinese Medicine, Jinan, Shandong 250011; ${ }^{4}$ Department of Otolaryngology, \\ Qianfoshan Hospital Affiliated to Shandong University, Jinan, Shandong 250014, P.R. China
}

Received February 12, 2017; Accepted October 20, 2017

DOI: $10.3892 / \mathrm{etm} .2018 .5844$

\begin{abstract}
Slug is associated with the radioresistance of nasopharyngeal carcinoma (NPC) and the main current approach of treatment for NPC is radiotherapy. Hence, the aim of the current study was to determine the effect of Slug silencing on the radiosensitivity of NPC cells. Lentiviral-mediated transfection of Slug RNA interference (RNAi) in NPC cell line C666-1 was performed in vitro. Following Slug inhibition, its expression was detected using western blotting. A clonogenic survival assay and flow cytometry were then performed to evaluate the clonogenic cell survival, cell cycle distribution and apoptosis of C666-1 cells following irradiation. The results indicated that Slug RNAi decreased cell proliferation, and increased cell apoptosis and $\mathrm{G}_{0} / \mathrm{G}_{1}$ arrest. Thus, lentiviral-mediated transfection of Slug RNAi enhanced the radiosensitivity of the NPC cell line C666-1, and Slug may therefore be a potential target to improve radiotherapy in treatment of NPC and reduce the radioresistance of NPC.
\end{abstract}

\section{Introduction}

Nasopharyngeal carcinoma (NPC) is endemic in Southern China (1). It was the eighth most common type of cancer in 2010, and accounted for $3.5 \%$ of all new cancer cases worldwide (2). Genetic susceptibility and Epstein-Barr virus infection are important etiological factors in NPC (3). For decades, the primary treatment strategies used for NPC were chemotherapy and radiotherapy $(4,5)$. Recently, the platinum

Correspondence to: Dr Shudong Yu, Department of Otolaryngology, Qianfoshan Hospital Affiliated to Shandong University, 16766 Jingshi Road, Jinan, Shandong 250014, P.R. China

E-mail: articlesreview@163.com

*Contributed equally

Abbreviation: NPC, nasopharyngeal carcinoma

Key words: slug, lentivirus, radiosensitivity, NPC doublet of fluorouracil plus cisplatin reigned as a first-line treatment strategy for chemotherapy (2). However, its efficacy remains controversial. Radiotherapy was the mainstay treatment for NPC due to its relatively high radiosensitivity and deep-seated anatomical position, which made surgical resection challenging (6). In addition, great technological advances have been made in radiotherapy, including three-dimensional conformal radiotherapy and intension-modulated radiotherapy $(7,8)$. However, due to irradiation resistance, some patients with NPC present with metastases following radiotherapy (5). Hence, enhancing the radiosensitivity of NPC may provide a novel treatment strategy for NPC.

Slug is a conserved zinc finger transcription factor, which belongs to the Snail family and presents an anti-apoptotic effect by regulating the transactivation of p53 upregulated modulator of apoptosis (PUMA) and the expression of B cell lymphoma-2 (Bcl-2) and Bcl-2-associated X protein $(9,10)$. It has been demonstrated that Slug-deficient cells are radiosensitive to DNA damage $(11,12)$. Slug inhibition also increases the radiosensitivity of HSC3 and HSC6 cells by upregulating PUMA in oral squamous carcinoma (13). In addition, Slug expression inhibits calcitriol-mediated sensitivity to radiation in colorectal cancer (14) and upregulates radiation-induced PUMA in cholangiocarcinoma (15). However, whether Slug inhibition may enhance radiosensitivity of NPC remains unknown.

Radio-gene therapy has been developed as a novel strategy, which combines traditional radiotherapy with gene therapy $(16,17)$. Due to radiation resistance, radiotherapy is sometimes ineffective, resulting in worse side effects (18). Therefore, it is necessary to understand the radiosensitive tumor targets and mechanisms underlying the development of radioresistance.

Thus, the aim of the present study was to investigate whether Slug inhibition may increase the radiosensitivity of NPC cell line C666-1. Following combined treatment of lentivirus-mediated Slug RNA interference (RNAi) transfection with X-ray irradiation, the expression of Slug was decreased, which resulted in increased irradiation (IR)-induced $G_{0} / G_{1}$ arrest and cell apoptosis of C666-1. These findings may offer novel insights into radiotherapy with gene therapy in the treatment of NPC. 


\section{Materials and methods}

Cell culture. Human NPC cell line C666-1 was obtained from the Xiangya Central Experiment Laboratory (Central South University, Hunan, China). Cells were cultured in RPMI-1640 media (GE Healthcare Life Sciences, Logan, UT, USA) supplemented with $10 \%$ fetal bovine serum (Hangzhou Sijiqing Biological Engineering Materials Co., Ltd., Hangzhou, China), $50 \mathrm{U} / \mathrm{ml}$ penicillin $\mathrm{G}$ and $50 \mathrm{U} / \mathrm{ml}$ streptomycin (Gibco; Thermo Fisher Scientific, Inc., Waltham, MA, USA) with $5 \% \mathrm{CO}_{2}$ in a humidified atmosphere at $37^{\circ} \mathrm{C}$. The cells were passaged every 3 days.

Irradiation procedure. Irradiation was performed with a single dose of X-rays ranging from 1-8 Gy using a linear accelerator (Trilogy, Austin, TX, USA) with $6 \mathrm{MV}$ photons $/ 100 \mathrm{~cm}$ focus-surface distance at room temperature. The dose rate was $4.0 \mathrm{~Gy} / \mathrm{min}$, which was determined by Fricke's chemical dosimeter (19).

Construction of lentiviral vectors. In order to produce lentivirus expressing RNAi specific for the Slug gene, the RNAi sequence for human Slug (GGAATATGTGAGCCTGGGC GCC) was identified using the BLOCK-iT RNAi Designer program (Invitrogen; Thermo Fisher Scientific, Inc.) and the negative control construct (control RNAi) was created using a scrambled sequence (GAACCGTGTCTTCCTCAGTATC). The two sequences were annealed and cloned into the AgeI and $E c o$ RI enzyme sites of pGCSIL-GFP vector $(500 \mathrm{ng} / \mu \mathrm{l}$; Shanghai Genechem Co., Ltd., Shanghai, China), respectively. Following confirmation of the constructed plasmids by DNA sequencing, lentiviral vector DNA and packaging vectors $(1 \mu \mathrm{g} / \mathrm{ml}$; pHelper 1.0 and pHelper 2.0; Shanghai Genechem Co., Ltd.) were then transfected into 293T cells (Sangon Biotech, Co., Ltd., Shanghai, China) using Lipofectamine 2000 (Invitrogen; Thermo Fisher Scientific, Inc.). Following 48 h of culture, supernatants containing lentiviruses, including pGCSIL-Slug-shRNA-LV and pGCSIL-neg-shRNA-LV were harvested, respectively. Purification was then performed at $1,000 \mathrm{x} \mathrm{g}$ and $4^{\circ} \mathrm{C}$ for $2 \mathrm{~min}$ using ultracentrifugation (Himac CT15RE; Hitachi, Tokyo, Japan) and the titer of lentivirus was determined. The lentiviruses were stored for 1 week in $-80^{\circ} \mathrm{C}$ and prepared for infection.

Infection of lentivirus. C666-1 cells were cultured in $60-\mathrm{mm}$ dishes with $5 \times 10^{5}$ cells in each plate. Cells were cultured in complete medium with lentiviruses at a multiplicity of infection of 10 for $24 \mathrm{~h}$ at $37^{\circ} \mathrm{C}$. Fresh culture medium was then used to substitute the old media. Total protein was isolated and the expression of Slug was detected by western blotting. Three groups of C666-1 cells were used in subsequent assays: CON group, a blank control group with no infection; NC group, a negative control group infected with pGCSIL-neg-shRNA-LV; and KD group, a Slug RNAi group infected with pGCSIL-Slug-shRNA-LV.

Western blot analysis. Cell extracts were prepared in radioimmunoprecipitation (RIPA) assay buffer ( $150 \mathrm{mM} \mathrm{NaCl}, 0.1 \%$ SDS, $0.5 \%$ sodium deoxycholate, $1 \%$ Nonidet P- 40 and $50 \mathrm{mM}$ Tris, $\mathrm{pH}$ 8.0), with the addition of $2 \mathrm{mM}$ phenylmethylsulfonyl fluoride. RIPA lysis buffer was freshly prepared and added to infected cells in 6-well plates (100 $\mu \mathrm{l} /$ well) on ice, which were then incubated for $10 \mathrm{~min}$. Protein concentrations were determined by BCA method with a protein assay kit. Equal amounts of proteins (10 $\mu \mathrm{g} /$ condition) were boiled for $10 \mathrm{~min}$ in loading buffer (Thermo Fisher Scientific, Inc.) prior to being separated on $15 \%$ SDS-PAGE. Separated proteins were then transferred to polyvinylidene difluoride membranes at $100 \mathrm{~V}$ for $1 \mathrm{~h}$ prior to membrane blocking in PBS with 5\% skim milk powder and Tween-20 at room temperature for $2 \mathrm{~h}$. Membranes were then incubated with anti-Slug primary antibody (cat. no. $9585 ; 1: 5,000$ ) and anti-GAPDH primary antibody (cat. no. 2118L; 1:3,000) (both from Cell Signaling Technology, Inc., Danvers, MA, USA) at $4^{\circ} \mathrm{C}$ overnight. Goat anti-rabbit horse radish peroxidase-conjugated secondary antibodies (cat. no. ab205718; Abcam, Cambridge, UK) were diluted 1:1,000 with PBST buffer and membranes were incubated for $60 \mathrm{~min}$ at room temperature. Membranes were washed three times using PBST prior to each step. Protein bands were visualized using an enhanced chemiluminescence system (Pierce; Thermo Fisher Scientific, Inc.). The images were captured and analyzed using ImageJ software 1.51e (National Institutes of Health, Bethesda, MD, USA).

Clonogenic cell survival. Cells $\left(5 \times 10^{5}\right)$ were seeded in culture dishes with Dulbecco's modified Eagle's medium (10\% fetal bovine serum; Thermo Fisher Scientific, Inc.) and irradiated the next day at the 4 Gy dose according to the reference (20). A total of $24 \mathrm{~h}$ following irradiation, cells were trypsinized, plated in $60-\mathrm{mm}$ dishes and incubated for 14 days at $37^{\circ} \mathrm{C}$ to allow colony growth. Colonies were fixed with $10 \%$ methanol for 8 min stained with Giemsa for 5-10 min at room temperature and colonies containing $>50$ cells were counted using a light microscope and x200 magnification. The survival fraction (SF) was calculated as: [(Mean colonies counted)/(cells plated) $\mathrm{x}$ (plating efficiency)]; plating efficiency was defined as: [(Mean colonies counted)/(cells plated)] for unirradiated controls ( $0 \mathrm{~Gy})$. The data were fit into the multi-target single-hit mathematical model (21) and survival curves for the three groups were created. Radiobiological parameters, including the SF at 2 Gy (SF2), mean lethal dose (D0), quasi-threshold dose $(\mathrm{Dq})$ and the extrapolate number $(\mathrm{N})$ were calculated according to the survival curves.

Cell cycle analysis. A total of $24 \mathrm{~h}$ following irradiation with 4 Gy X-rays, cells were washed twice with PBS and harvested by trypsinization. Cells were then fixed with $70 \%$ ethanol at $-20^{\circ} \mathrm{C}$ and resuspended in $20 \mu \mathrm{g} / \mathrm{ml}$ propidium iodide (PI; Abcam) for $30 \mathrm{~min}$ at $4^{\circ} \mathrm{C}$. DNA content was detected using a flow cytometer (FACSCalibur ${ }^{\mathrm{TM}}$; BD Biosciences, Franklin Lakes, NJ, USA). The relative proportion of cells in the individual cell cycle phase fraction was determined by the flow cytometry data using FCSExpress 3.0 (De Novo Software, Glendale, CA, USA).

Apoptosis assay. A total of $24 \mathrm{~h}$ following exposure to $4 \mathrm{~Gy}$ $\mathrm{X}$-rays, cells were stained with Annexin V-allphycocyanin (APC)/PI (Abcam) for $15 \mathrm{~min}$ at room temperature to measure cell apoptosis. A total of $1.0 \times 10^{6}$ cells were washed twice with ice-cold PBS and incubated for $30 \mathrm{~min}$ in binding buffer 
A

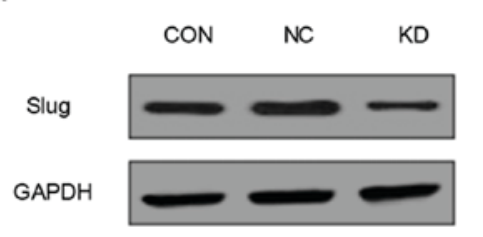

B

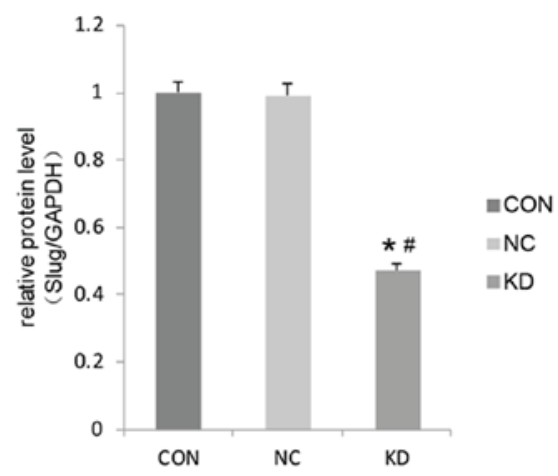

Figure 1. Lentiviral vectors encoding Slug RNAi or control RNAi were constructed and transfected into C666-1 cells, with untreated C666-1 cells serving as a control. (A) The expression of Slug was detected using western blotting. (B) Quantification of western blot results relative to GAPDH. Values are expressed as the mean \pm standard deviation. All experiments were performed in triplicate. ${ }^{*} \mathrm{P}<0.05$ vs. NC group; ${ }^{\text {"P }}<0.05$ vs. CON group. RNAi, RNA interference; CON, control group consisting of untreated C666-1 cells; NC, negative control consisting of C666-1 cells infected with pGCSIL-neg-shRNA-LV; KD, Slug RNAi group consisting of C666-1 cells infected with pGCSIL-Slug-shRNA-LV.

at room temperature. Fluorescence-activated cell sorting analysis for Annexin V-APC/PI staining was performed by flow cytometry (FACSCalibur ${ }^{\mathrm{TM}}$; BD Biosciences) with FCS Express 3.0 software. Cells that stained positive for Annexin V and negative for PI were undergoing apoptosis. Cells that stained positive for Annexin V and PI were either in the end of stage of apoptosis, undergoing necrosis or were already dead. Cells that stained negative for Annexin V and PI were alive and not undergoing measurable apoptosis.

Statistical analysis. All experiments were performed in triplicate and data were expressed as the mean \pm standard deviation. Statistically significant differences between groups were determined using one way analysis of variance followed by the Tukey's post hoc multiple comparison test using SPSS 17.0 (SPSS, Inc., Chicago, IL, USA). P $<0.05$ was considered to indicate a statistically significant difference. The survival curve was drawn using Sigma Plot 12.0 (Systat Software, Inc., San Jose, CA, USA).

\section{Results}

Slug is downregulated by lentivirus-mediated RNAi in C666-1 cells. A lentivirus vector system derived from HIV-1 was used to express short hairpin RNA (shRNA) directed against Slug to downregulate its expression in C666-1 cells. The effect of lentivirus-mediated RNAi knockdown of Slug on its expression was determined using western blot analysis. The expression of Slug in the KD group was significantly decreased compared with that in the CON and NC groups (Fig. 1). The difference in Slug expression between the CON group and the NC group was not significant. Thus, these results confirmed the downregulation of Slug in the C666-1-transfected cell line.

Slug inhibition increases radiosensitivity and decreases cell survival of C666-1. The effects of Slug inhibition in combination with X-ray irradiation on C666-1 cell survival was investigated using a clonogenic survival assay. The results indicated that Slug inhibition significantly increased cell sensitivity to X-ray irradiation compared with the level of sensitivity observed in the NC group and CON group (Fig. 2). The values of SF2, D0, Dq and $\mathrm{N}$ for the KD group were
Table I. Survival curve parameters fitting the data into a multi-target single-hit model.

\begin{tabular}{llll}
\hline & \multicolumn{3}{c}{ Groups } \\
\cline { 2 - 4 } Parameter & CON & NC & KD \\
\hline D0 & 2.269 & 2.226 & $1.988^{\mathrm{a}}$ \\
Dq & 2.128 & 2.078 & $1.338^{\mathrm{b}}$ \\
$\mathrm{N}$ & 3.724 & 3.596 & $1.916^{\mathrm{c}}$ \\
SF2 & 0.855 & 0.823 & $0.576^{\mathrm{d}}$ \\
\hline
\end{tabular}

D0, mean lethal dose; Dq, quasi-threshold dose; N, extrapolation number; SF2, surviving fraction at $2 \mathrm{~Gy}$; $\mathrm{CON}$, control group consisting of untreated C666-1 cells; $\mathrm{NC}$, negative control consisting of C666-1 cells infected with pGCSIL-neg-shRNA-LV; KD, Slug RNA interference group consisting of C666-1 cells infected with pGCSIL-Slug-shRNA-LV. ${ }^{\mathrm{a}} \mathrm{P}<0.05$ vs. D0 in the $\mathrm{NC}$ and CON groups; ${ }^{\mathrm{b}} \mathrm{P}<0.05$ vs. $\mathrm{Dq}$ in the $\mathrm{NC}$ and $\mathrm{CON}$ groups; ${ }^{\mathrm{c}} \mathrm{P}<0.05$ vs. $\mathrm{N}$ in the $\mathrm{NC}$ and $\mathrm{CON}$ groups; ${ }^{\mathrm{d}} \mathrm{P}<0.05$ vs. $\mathrm{SF} 2$ in the $\mathrm{NC}$ and $\mathrm{CON}$ groups.

all decreased significantly compared with those in the CON and NC groups (Table I). SF2 was reduced to $57.6 \%$ in the $\mathrm{KD}$ group from $85.5 \%$ in the CON group, and the sensitization enhancement ratio was 1.48 (data now shown). In addition, the results indicated that cell colony forming efficiency was decreased in the KD group compared with that observed in the NC group following irradiation treatment (Fig. 2). There were few visible colonies that were able to be easily seen with the naked eye that were irradiated with $4 \mathrm{~Gy}$ in the KD group in comparison with the CON and NC groups (Fig. 2).

Effect of Slug inhibition combined with X-ray irradiation on the C666-1 cell cycle. The impact of Slug inhibition and X-ray irradiation on the cell cycle was also investigated. Analysis indicated that Slug inhibition and X-ray irradiation induced a significant increase in the $\mathrm{G}_{0} / \mathrm{G}_{1}$ phase $(56.09 \pm 1.07 \%$ NC group vs. $72.21 \pm 1.38 \% \mathrm{KD}$ group) and decrease in the $\mathrm{S}$ phase in the proportion of cells $(32.13 \pm 1.14 \% \mathrm{NC}$ group vs. $15.17 \pm 1.16 \%$ $\mathrm{KD}$ group) in the KD group compared with the proportion in 
A

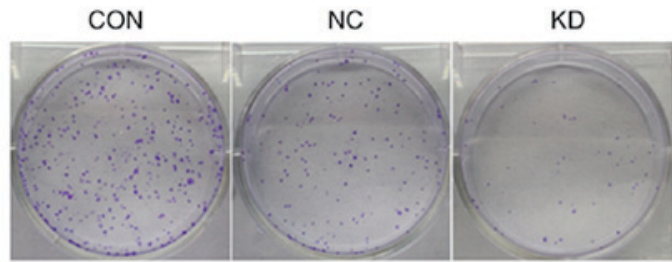

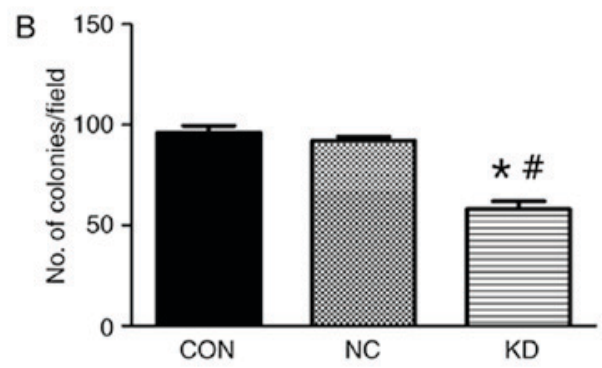

Figure 2. Clonogenic assay was used to observe the survival of C666-1 cells. (A) A clonogenic assay was used to detect the colony formation ability of cells following irradiation at $4 \mathrm{~Gy}$. (B) Quantification of the number of colonies of C666-1 cells. Values are expressed as the mean \pm standard deviation. All experiments were performed in triplicate. $\mathrm{P}<0.05$ vs. $\mathrm{NC}$ group; ${ }^{*} \mathrm{P}<0.05$ vs. $\mathrm{CON}$ group. $\mathrm{CON}$, control group consisting of untreated C666-1 cells; $\mathrm{NC}$, negative control consisting of C666-1 cells infected with pGCSIL-neg-shRNA-LV; KD, Slug RNAi group consisting of C666-1 cells infected with pGCSIL-Slug-shRNA-LV.

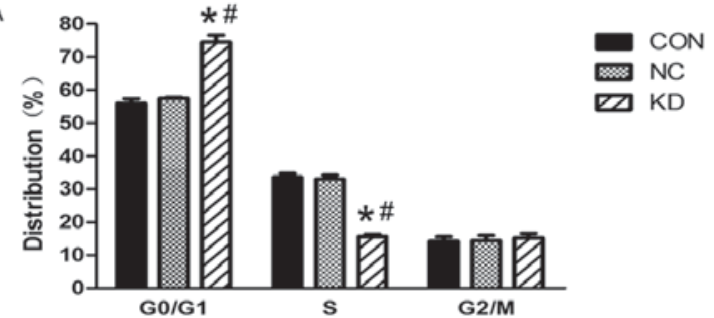

B

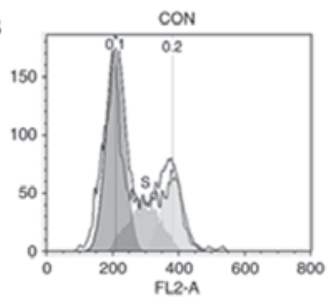

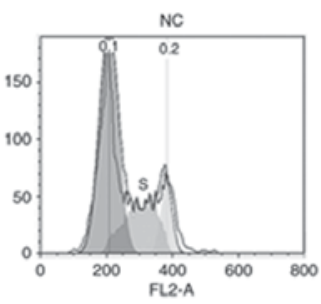

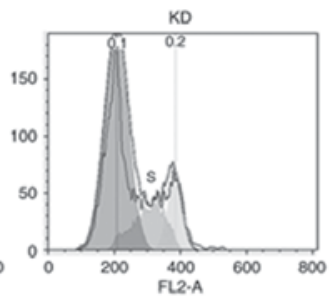

Figure 3. Changes in the cell cycle following irradiation at $4 \mathrm{~Gy}$ in C666-1 cells treated with Slug RNAi. (A) Proportion of cells in the $\mathrm{G}_{0} / \mathrm{G}_{1}$ and $\mathrm{S}$ phases of the cell cycle in the NC, CON and KD groups. (B) C666-1 cell cycles were detected using flow cytometry analysis in the different groups. Values are expressed as the mean \pm standard deviation. All experiments were performed in triplicate. ${ }^{*} \mathrm{P}<0.05$ vs. NC group; ${ }^{\#} \mathrm{P}<0.05$ vs. CON group. RNAi, RNA interference; $\mathrm{CON}$, control group consisting of untreated C666-1 cells; NC, negative control consisting of C666-1 cells infected with pGCSIL-neg-shRNA-LV; KD, Slug RNAi group consisting of C666-1 cells infected with pGCSIL-Slug-shRNA-LV; $\mathrm{G}_{0}$, resting phase; $\mathrm{G}_{1}$, gap 1 phase; $\mathrm{S}$, synthesis phase; $\mathrm{G}_{2}$, gap 2 phase; $\mathrm{M}_{\text {, mitotic }}$ phase.
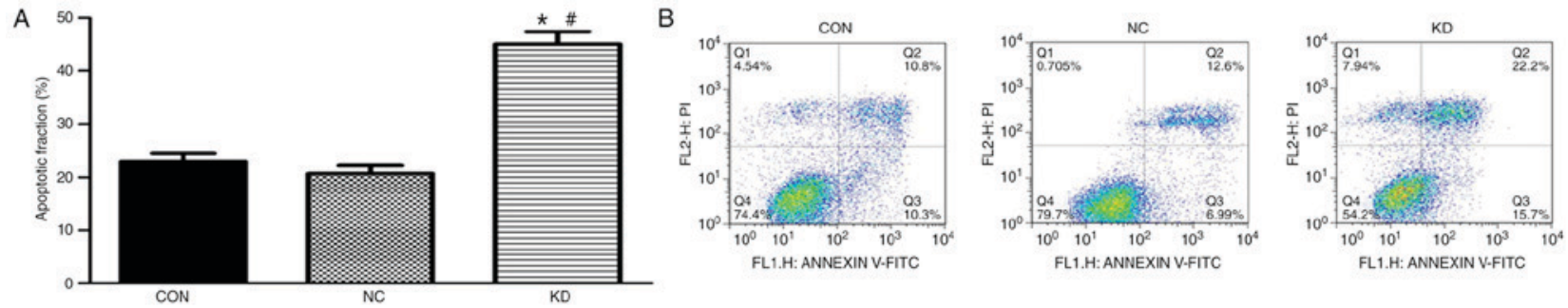

Figure 4. Apoptosis ratio of C666-1 cells treated with Slug RNAi following irradiation at 4 Gy. (A) Percentage of apoptotic C666-1 cells in the CON, NC and KD groups. (B) Apoptosis was determined using flow cytometry analysis in the different groups. Values are expressed as the mean \pm standard deviation. All experiments were performed in triplicate. ${ }^{*} \mathrm{P}<0.05$ vs. NC group; ${ }^{*} \mathrm{P}<0.05$ vs. NC group. RNAi, RNA interference; $\mathrm{CON}$, control group consisting of untreated C666-1 cells; NC, negative control consisting of C666-1 cells infected with pGCSIL-neg-shRNA-LV; KD, Slug RNAi group consisting of C666-1 cells infected with pGCSIL-Slug-shRNA-LV; FITC, fluorescein isothiocyanate; PI, propidium iodide.

the NC group (Fig. 3). The frequency of cells with a downregulated expression of Slug in the S phase was significantly decreased in the KD group compared with that in the CON group and NC group. These results indicate that Slug inhibition combined with X-ray irradiation increased the number of cells in the $\mathrm{G}_{0} / \mathrm{G}_{1}$ phase of the cell cycle.

Slug inhibition combined with X-ray irradiation increases apoptosis of C666-1 cells. The impact of Slug inhibition combined with X-ray irradiation treatment on C666-1 cell apoptosis was evaluated using flow cytometry analysis. The percentage of apoptotic cells in the KD group was significantly increased compared with that in the $\mathrm{NC}$ and CON groups (Fig. 4). The percentage of apoptotic cells in the CON and NC groups were $22.91 \pm 0.41$ and $20.61 \pm 0.38 \%$ respectively, while the percentage of apoptotic cells in the KD group was $45.12 \pm 0.65 \%$. These results suggest that apoptosis was increased in cells with downregulated expression of Slug following irradiation compared with that observed in the control groups.

\section{Discussion}

NPC is an epithelial malignancy arising in the head and neck region of the body (22). It is prevalent in Southern China with an annual incidence of 20/100,000 people (23). The 'gold standard' of treatment for NPC is radiotherapy, which has a cure rate of $>90 \%$ in patients with early-stage NPC (24). However, due 
to radiation resistance, the efficacy of radiotherapy is limited, especially in advanced stages of NPC. Hence, decreasing the radiation resistance and increasing radiosensitivity is a method that may improve the efficacy of radiotherapy in patients with NPC.

The Slug protein belongs to the Snail superfamily of zinc finger transcription factors, which is associated with embryonic development, regulation of carcinogenesis in various cancer types and anti-apoptosis (25-29). It has been demonstrated that Slug may be involved in the radioresistance of different types of cancer, including colorectal cancer, cholangiocarcinoma and ovarian cancer $(14,15,30,31)$. However, there have been few studies on the function of Slug in association with radioresistance in NPC. Therefore, the present study investigated the effect of Slug inhibition on the radiosensitivity of NPC cell line C666-1.

The effect of Slug inhibition on the radiosensitivity of NPC cell line C666-1 was investigated by downregulating the expression of Slug by infecting the cells with Slug-specific RNAi-expressing lentivirus. Following downregulation, the expression of Slug was significantly decreased. A clonogenic survival assay was then performed, which suggested that the downregulation of Slug decreased clonogenic survival. In addition, Slug inhibition increased the number of cells in the $\mathrm{G}_{0} / \mathrm{G}_{1}$ phase, while the number in the $\mathrm{S}$ phase was decreased. Furthermore, a cell apoptosis assay was applied to measure cell apoptosis following X-ray irradiation in combination with Slug downregulation. The results indicated that Slug inhibition induced cell apoptosis following irradiation. Slug inhibition may therefore, increase the radiosensitivity of NPC via the induction of apoptosis and cell cycle arrest.

It has been demonstrated that Slug serves a role in the radioresistance of several types of cancer $(31,32)$. However, the mechanisms underlying the radioresistance of cancer remain unclear. PUMA is a pivotal protein in apoptosis and it has been suggested that PUMA may increase sensitivity to radiation-induced apoptosis in different types of cancer $(15,33,34)$. Slug is a suppressor of PUMA transcription, which inhibits the expression of PUMA resulting in cell survival (35). Therefore, it may be hypothesized that Slug, as a radioprotection agent, may serve an important role in decreasing radiosensitivity by inhibiting the expression of PUMA. Following the downregulation of Slug, it has been demonstrated that PUMA increases cell apoptosis and sensitivity to radiation (13). In future studies, further investigation of the pathways involved in the development of NPC is required.

In conclusion, the results of the current study indicated that Slug may be a potential target of radio-gene therapy to increase the radiosensitivity of NPC.

\section{References}

1. Cancer incidence in five continents. Volume VIII. IARC Sci Publ: 1-781, 2002.

2. Chua MLK, Wee JTS, Hui EP and Chan ATC: Nasopharyngeal carcinoma. Lancet 387: 1012-1024, 2016.

3. Cui Q, Feng FT, Xu M, Liu WS, Yao YY, Xie SH, Li XZ, Ye ZL, Feng QS, Chen LZ, et al: Nasopharyngeal carcinoma risk prediction via salivary detection of host and Epstein-Barr virus genetic variants. Oncotarget 8: 95066-95074, 2016.

4. Chua ML and Chan AT: Gemcitabine: A game changer in nasopharyngeal carcinoma. Lancet 388: 1853-1854, 2016.
5. Xiao WW, Han F, Lu TX, Chen CY, Huang Y and Zhao C: Treatment outcomes after radiotherapy alone for patients with early-stage nasopharyngeal carcinoma. Int J Radiat Oncol Biol Phys 74: 1070-1076, 2009.

6. Brennan B: Nasopharyngeal carcinoma. Orphanet J Rare Dis 1: 23, 2006.

7. Waldron J, Tin MM, Keller A, Lum C, Japp B, Sellmann S, van Prooijen M, Gitterman L, Blend R, Payne D, et al: Limitation of conventional two dimensional radiation therapy planning in nasopharyngeal carcinoma. Radiother Oncol 68: 153-161, 2003.

8. Uzel EK, Karaçam S, Eliçin O and Uzel O: Comparison of two different IMRT planning techniques in the treatment of nasopharyngeal carcinoma. Effect on parotid gland radiation doses. Strahlenther Onkol 189: 552-558, 2013.

9. Xu T, Fan B, Lv C and Xiao D: Slug mediates nasopharyngeal carcinoma radioresistance via downregulation of PUMA in a p53-dependent and -independent manner. Oncol Rep 33: 2631-2638, 2015

10. Lee SH, Kim DY, Jing F, Kim H, Yun CO, Han DJ and Choi EY: Del-1 overexpression potentiates lung cancer cell proliferation and invasion. Biochem Biophys Res Commun 468: 92-98, 2015.

11. Pérez-Losada J, Sánchez-Martín M, Pérez-Caro M, Pérez-Mancera PA and Sánchez-García I: The radioresistance biological function of the $\mathrm{SCF} /$ kit signaling pathway is mediated by the zinc-finger transcription factor Slug. Oncogene 22: 4205-4211, 2003.

12. Pérez-Caro M, Bermejo-Rodríguez C, González-Herrero I, Sánchez-Beato M, Piris MA and Sánchez-García I: Transcriptomal profiling of the cellular response to DNA damage mediated by Slug (Snai2). Br J Cancer 98: 480-488, 2008.

13. Jiang F, Zhou L, Wei C, Zhao W and Yu D: Slug inhibition increases radiosensitivity of oral squamous cell carcinoma cells by upregulating PUMA. Int J Oncol 49: 709-719, 2016.

14. Findlay VJ, Moretz RE, Wang C, Vaena SG, Bandurraga SG, Ashenafi M, Marshall DT, Watson DK and Camp ER: Slug expression inhibits calcitriol-mediated sensitivity to radiation in colorectal cancer. Mol Carcinog 53 (Suppl 1): E130-E139, 2014.

15. Zhang K, Zhang B, Lu Y, Sun C, Zhao W, Jiao X, Hu J, Mu P, Lu $\mathrm{H}$ and Zhou C: Slug inhibition upregulates radiation-induced PUMA activity leading to apoptosis in cholangiocarcinomas. Med Oncol 28 (Suppl 1): S301-S309, 2011.

16. Zhao Y, Li Z, Sheng W, Miao J and Yang J: Radiosensitivity by ING4-IL-24 bicistronic adenovirus-mediated gene cotransfer on human breast cancer cells. Cancer Gene Ther 20: 38-45, 2013.

17. Finnon P, Kabacik S, MacKay A, Raffy C, A'Hern R, Owen R, Badie C, Yarnold $\mathrm{J}$ and Bouffler S: Correlation of in vitro lymphocyte radiosensitivity and gene expression with late normal tissue reactions following curative radiotherapy for breast cancer. Radiother Oncol 105: 329-336, 2012.

18. Markant SL, Esparza LA, Sun J, Barton KL, McCoig LM, Grant GA, Crawford JR, Levy ML, Northcott PA, Shih D, et al: Targeting sonic hedgehog-associated medulloblastoma through inhibition of Aurora and Polo-like kinases. Cancer Res 73: 6310-6322, 2013

19. Meesat R, Sanguanmith S, Meesungnoen J, Lepage M, Khalil A and Jay-Gerin JP: Utilization of the ferrous sulfate (Fricke) dosimeter for evaluating the radioprotective potential of cystamine: Experiment and Monte Carlo simulation. Radiat Res 177: 813-826, 2012.

20. Zhang SX, Qiu QH, Chen WB, Liang $\mathrm{CH}$ and Huang B: Celecoxib enhances radiosensitivity via induction of $\mathrm{G}_{2}-\mathrm{M}$ phase arrest and apoptosis in nasopharyngeal carcinoma. Cell Physiol Biochem 33: 1484-1497, 2014.

21. Spring E and Holmberg P: Evaluation of experimental irradiation fractionation with the single-hit, multi-target model. Acta Radiol Ther Phys Biol 7: 297-306, 1968.

22. Ma BB, Hui EP and Chan AT: Systemic approach to improving treatment outcome in nasopharyngeal carcinoma: Current and future directions. Cancer Sci 99: 1311-1318, 2008.

23. Razak AR, Siu LL, Liu FF, Ito E, O'Sullivan B and Chan K: Nasopharyngeal carcinoma: The next challenges. Eur J Cancer 46: 1967-1978, 2010.

24. Chan AT: Current treatment of nasopharyngeal carcinoma. Eur J Cancer 47 (Suppl 3): S302-S303, 2011.

25. Nieto MA: The snail superfamily of zinc-finger transcription factors. Nat Rev Mol Cell Biol 3: 155-166, 2002.

26. Ros MA, Sefton M and Nieto MA: Slug, a zinc finger gene previously implicated in the early patterning of the mesoderm and the neural crest, is also involved in chick limb development. Development 124: 1821-1829, 1997. 
27. Shih JY and Yang PC: The EMT regulator slug and lung carcinogenesis. Carcinogenesis 32: 1299-1304, 2011.

28. Wu WS, Heinrichs S, Xu D, Garrison SP, Zambetti GP, Adams JM and Look AT: Slug antagonizes p53-mediated apoptosis of hematopoietic progenitors by repressing puma. Cell 123: 641-653, 2005

29. Inukai T, Inoue A, Kurosawa H, Goi K, Shinjyo T, Ozawa K, Mao M, Inaba T and Look AT: SLUG, a ces-1-related zinc finger transcription factor gene with antiapoptotic activity, is a downstream target of the E2A-HLF oncoprotein. Mol Cell 4: 343-352, 1999.

30. Arienti C, Tesei A, Carloni S, Ulivi P, Romeo A, Ghigi G, Menghi E, Sarnelli A, Parisi E, Silvestrini R and Zoli W: SLUG silencing increases radiosensitivity of melanoma cells in vitro. Cell Oncol (Dordr) 36: 131-139, 2013.

31. Kurrey NK, Jalgaonkar SP, Joglekar AV, Ghanate AD Chaskar PD, Doiphode RY and Bapat SA: Snail and slug mediate radioresistance and chemoresistance by antagonizing p53-mediated apoptosis and acquiring a stem-like phenotype in ovarian cancer cells. Stem Cells 27: 2059-2068, 2009.
32. Zhang P, Liu H, Xia F, Zhang QW, Zhang YY, Zhao Q, Chao ZH, Jiang ZW and Jiang CC: Epithelial-mesenchymal transition is necessary for acquired resistance to cisplatin and increases the metastatic potential of nasopharyngeal carcinoma cells. Int J Mol Med 33: 151-159, 2014.

33. Kuribayashi K, Finnberg N, Jeffers JR, Zambetti GP and El-Deiry WS: The relative contribution of pro-apoptotic p53-target genes in the triggering of apoptosis following DNA damage in vitro and in vivo. Cell Cycle 10: 2380-2389, 2011.

34. Wang R, Wang X, Li B, Lin F, Dong K, Gao P and Zhang HZ: Tumor-specific adenovirus-mediated PUMA gene transfer using the survivin promoter enhances radiosensitivity of breast cancer cells in vitro and in vivo. Breast Cancer Res Treat 117: 45-54, 2009.

35. Kim S, Yao J, Suyama K, Qian X, Qian BZ, Bandyopadhyay S, Loudig O, De Leon-Rodriguez C, Zhou ZN, Segall J, et al: Slug promotes survival during metastasis through suppression of Puma-mediated apoptosis. Cancer Res 74: 3695-3706, 2014. 